\title{
Technical Note: The MESSy-submodel AIRSEA calculating the air-sea exchange of chemical species
}

\author{
A. Pozzer, P. Jöckel, R. Sander, J. Williams, L. Ganzeveld, and J. Lelieveld \\ Max Planck Institute for Chemistry, Mainz, Germany \\ Received: 15 June 2006 - Published in Atmos. Chem. Phys. Discuss.: 29 August 2006 \\ Revised: 22 November 2006 - Accepted: 23 November 2006 - Published: 5 December 2006
}

\begin{abstract}
The new submodel AIRSEA for the Modular Earth Submodel System (MESSy) is presented. It calculates the exchange of chemical species between the ocean and the atmosphere with a focus on organic compounds. The submodel can be easily extended to a large number of tracers, including highly soluble ones. It is demonstrated that the application of explicitly calculated air-sea exchanges with AIRSEA can induce substantial changes in the simulated tracer distributions in the troposphere in comparison to a model setup in which this process is neglected. For example, the simulations of acetone, constrained with measured oceanic concentrations, shows relative changes in the atmospheric surface layer mixing ratios over the Atlantic Ocean of up to $300 \%$.
\end{abstract}

\section{Introduction}

Recently, increasing attention has been given to gas exchange between the ocean and the atmosphere. Oceans have generally been considered very important for the atmosphere (e.g. for moisture and heat transport), while in the last decade their significance for the budgets of many atmospheric chemical species (tracers) has also been recognised, with an increasing interest in volatile organic compounds (VOC) and their oxidation products (OVOC) (Singh et al., 2001; Marandino et al., 2005; Plass-Dülmer et al., 1995; Sinha et al., 2006). So far, modelling studies of global air-sea exchanges, focusing on organic compounds, have only been performed for a few specific cases and/or tracers (e.g. Carpenter et al. (2004), Berner et al. (2003) or Kettle and Andreae (2000)), whereas no comprehensive simulations with general circulation models (GCMs) have been performed. The atmosphere-ocean exchange of gases is critical for a

Correspondence to: A. Pozzer

(pozzer@mpch-mainz.mpg.de) good representation of many OVOCs in the troposphere and hence of ozone and other oxidants.

Here we present AIRSEA, a new submodel for the Modular Earth Submodel System (MESSy) by Jöckel et al. (2005). AIRSEA is used to calculate these exchange processes in global models. The submodel has been tested with organic compounds (methanol, acetone, propane, propene, $\mathrm{CO}_{2}$ and dimethylsulfide DMS).

However, due to its generality, AIRSEA can be easily extended to many other tracers with only few restrictions: gases for which aqueous phase dissociation is important or acids and bases with a $\mathrm{pH}$-dependent solubility. A typical example is ozone $\left(\mathrm{O}_{3}\right)$, which reacts so quickly in surface water that the deposition velocity is $\approx 40$ times enhanced.

\section{Submodel description}

In AIRSEA, the two-layer model presented by Liss and Slater (1974) has been adopted. This model is based on the assumption that close to the air-sea interface each fluid is well mixed, and that within the interface between water and air the exchange is solely driven by molecular diffusion. The two layer model has been used to first introduce a more mechanistic representation of air-sea exchanges, whereas more recent approaches will be used in the future e.g. Asher and Pankow (1991).

The model input includes concentrations in the uppermost ocean layer, where the fluid is well mixed by turbulence (due to wind stress). Assuming further that transport of gases across the interface is a steady state process, it follows (Liss and Slater, 1974) that the flux $F$ (in $\mathrm{mol} /\left(\mathrm{m}^{2} \mathrm{~s}\right)$ ) across the interface is

$F=K_{\text {tot }}\left(c_{w}-H p_{g}\right)$

where $c_{w}$ is the concentration of the tracer in water (in $\left.\mathrm{mol} / \mathrm{m}^{3}\right), H$ is the Henry's Law coefficient (in $\mathrm{mol} /\left(\mathrm{m}^{3} \mathrm{~Pa}\right)$ ), $p_{g}$ is the partial pressure (in $\mathrm{Pa}$ ) of the gas in air over the

Published by Copernicus GmbH on behalf of the European Geosciences Union. 
liquid surface and $K_{\text {tot }}$ is the transfer (or piston) velocity (in $\mathrm{m} / \mathrm{s})$.

The Henry's Law coefficient $H$ is calculated including the temperature dependence (Sander, 1999a-1999b and references therein). We define the Henry's Law coefficient as the ratio of the aqueous-phase concentration of a species to the partial pressure of the same species in the gas phase. Hence some of the following equations appear slightly different to those in the original references, mostly due to the different definition of the Henry's Law coefficient.

$K_{\text {tot }}$ can be defined as (Liss and Slater, 1974):

$$
\begin{aligned}
K_{\mathrm{tot}} & =\left(R_{w}+R_{g}\right)^{-1}=\left(\frac{1}{\alpha K_{w}}+\frac{H R T}{K_{g}}\right)^{-1}, \\
\frac{H R T}{K_{g}} & =R_{g}, \\
\frac{1}{\alpha K_{w}} & =R_{w} .
\end{aligned}
$$

$\alpha$ is an enhancement factor due to the species reaction in solution (dimensionless), $\mathrm{R}$ is the gas constant (8.31441 $\mathrm{Jmol}^{-1} \mathrm{~K}^{-1}$ ), $\mathrm{T}$ is the temperature (in $\mathrm{K}$ ), $K_{w}$ and $K_{g}$ are exchange velocities for the liquid and gas phase (in $\mathrm{m} / \mathrm{s}$ ), $R_{g}$ and $R_{w}$ (in $\mathrm{s} / \mathrm{m}$ ) are the resistances in the gas and liquid phase, respectively.

The salinity effect on the tracer's solubility is taken into account using the Setschenow equation:

$\ln \left(\frac{H}{H_{0}}\right)=-K_{s} c_{s}$

where $K_{S}$ is the Setschenow (or salting out) constant (in $\mathrm{L} / \mathrm{mol}$ ), $c_{s}$ (in $\mathrm{mol} / \mathrm{L}$ ) is the concentration of the salt in ocean water, and $H_{0}$ is the Henry's Law coefficient in distilled water. Xie et al. (1997) showed that for organic tracers the Setschenow constant $K_{S}$ can be approximated as

$$
K_{s}=0.0018 V_{x},
$$

where $V_{x}$ is the molar volume at the boiling point of the tracer (in $\mathrm{cm}^{3} / \mathrm{mol}$ ). Xie et al. (1997) showed further that this approximation (denoted as Xie and Mackay Volume calculation, XMV) leads to better estimates of $K_{S}$, compared to various experimental methods, which require assumptions about several parameters (Xie et al., 1990). However, more complex theoretical estimations of $K_{s}$ are also present in the literature. As pointed out by Ni et al. (2000, and references therein), the XMV method is by far the simplest and also one of the most accurate, with an average relative error of $\approx 11 \%$ in the estimation of $K_{s}$ for organic compounds. Nevertheless, it is highly recommended to check the calculated values with experimental data, if available. In AIRSEA the calculation following Eq. (6) is optionally included for all tracers. Climatological global monthly average maps of salinity are taken from the World Ocean Atlas (2001), by Boyer et al. (2002), in a $1^{\circ} \times 1^{\circ}$ resolution.
For $K_{w}$ different estimates exist, primarily based on combinations of field and laboratory studies, normalised to a Schmidt number of 660 , here called $\hat{K}_{w}$ in $\mathrm{cm} / \mathrm{h}$ (Liss and Merlivat, 1986; Wanninkhof, 1992; Wanninkhof and McGills, 1999; Nightingale et al., 2000).

Table 1 shows the most important parametrisations that have been reported in the literature. They are implemented in AIRSEA and can be selected via a namelist file, i.e. without recompiling the code. To be consistent with other MESSy submodels ONLEM, Kerkweg et al. (2006b), the parametrisation by Liss and Merlivat (1986) is set as default.

In AIRSEA, $\hat{K}_{w}$ is then scaled to the actual Schmidt number and transformed to m/s to obtain $K_{w}$, used in Eq. (4):

$K_{w}=\beta \times \hat{K}_{w} \times\left(\frac{\mathrm{Sc}_{\mathrm{liq}}}{660}\right)^{-n}$,

where $\beta$ is $2.8 \times 10^{-6}$ (necessary to convert from $\mathrm{cm} / \mathrm{h}$ to $\mathrm{m} / \mathrm{s}$ ) and $\mathrm{Sc}_{\text {liq }}$ is the dimensionless Schmidt number (in the liquid phase). The Schmidt number is defined as $v / D$, with the kinematic viscosity $v$ (in $\mathrm{m}^{2} \mathrm{~s}^{-1}$ ) and the molecular diffusivity $D\left(\right.$ in $\mathrm{m}^{2} \mathrm{~s}^{-1}$ ). The value of $n$ ranges from $2 / 3$ for a smooth surface to $1 / 2$ for a rough or wavy surface (Jähne et al., 1987). In AIRSEA a constant value of $n=1 / 2$ is used, with the exception of low-wind speed in the Liss and Merlivat (1986) parametrisation, where $2 / 3$ is used, coherently with Kerkweg et al. (2006b).

Due to the turbulent characteristics of the top ocean layer and the presence of bubbles, which can enhance the transfer, we adopted in addition to Eq. (7), an alternative parametrisation with an empirical coefficient for non-clean bubbles in the presence of white-caps (Asher and Wanninkhof, 1998a):

$$
\begin{gathered}
K_{w}=\left[\left(\kappa U_{10}+W_{c}\left(115200-\kappa U_{10}\right)\right) \mathrm{Sc}_{\mathrm{liq}}{ }^{-1 / 2}+\right. \\
\left.W_{c}\left(\frac{-37}{\alpha_{\mathrm{ost}}}+6120 \alpha_{\mathrm{ost}}^{-0.37} \mathrm{Sc}_{\mathrm{liq}}-0.18\right)\right] \times 2.8 \times 10^{-6} \mathrm{~m} / \mathrm{s}
\end{gathered}
$$

$\alpha_{\text {ost }}$ is the dimensionless Ostwald number and $\kappa=47 \mathrm{~s} / \mathrm{m}$. The fractional area coverage $W_{c}$ of actively breaking whitecaps is defined as (Monahan, 1993; Soloviev and Schluessel, 2002):

$W_{c}=c_{1}\left(U_{10}-c_{o}\right)^{3}$

with $c_{1}=2.56 \times 10^{-6} \mathrm{~s}^{3} \mathrm{~m}^{-3}$ and $c_{0}=1.77 \mathrm{~ms}^{-1}$.

The two alternatives (Eqs. 7 and 8) are selectable via the user interface (Fortran90 namelist); changes of the submodel code are not required.

It has to be stressed that Eq. (8) is strictly valid only for gases far from equilibrium Asher and Wanninkhof (1998a), Asher and Wanninkhof (1998b) .

The effect of bubbles on the transfer velocity has been characterised by Asher and Wanninkhof (1998a); it changes the exponent in Eq. (7). This influence on the exponent is very important for soluble gases. However, the understanding of this phenomenon is poor for gases close to equilibrium, and no parameterisation for the bubble entrainment is 
Table 1. Different parametrisations of $\hat{K_{w}}($ in $\mathrm{cm} / \mathrm{h})$ for calculations using instantaneous 10 meter wind speed $\left(U_{10}\right.$ in $\left.\mathrm{m} / \mathrm{s}\right)$.

\begin{tabular}{llr}
\hline & Reference & relationship \\
\hline & & $0.17 U_{10}$ for $U_{10}<3.6 \mathrm{~m} / \mathrm{s}$ \\
1 & Liss and Merlivat (1986) & $2.85 U_{10}-9.65$ for $3.6 \mathrm{~m} / \mathrm{s}<U_{10}<13 \mathrm{~m} / \mathrm{s}$ \\
& & $5.9 U_{10}-49.3$ for $13 \mathrm{~m} / \mathrm{s}<U_{10}$ \\
2 & Wanninkhof (1992) & $0.31\left(U_{10}\right)^{2}$ \\
3 & Wanninkhof and McGills (1999) & $0.0283\left(U_{10}\right)^{3}$ \\
4 & Nightingale et al. (2000) & $0.333\left(U_{10}\right)+0.222\left(U_{10}\right)^{2}$ \\
5 & Ho et al. (2006) & $0.266\left(U_{10}\right)^{2}$ \\
\hline
\end{tabular}

generally accepted. Hence a constant exponent of $n=1 / 2$ is used in Eq. (7).

Since precipitation can significantly increase the air-sea exchange, a parameterisation has been adopted (Ho et al., 2004), and the resulting transfer velocity has been added to the calculated $K_{w}$ only in the presence of rain :

$K_{w}^{\prime}=K_{w}+K_{w}^{(p)}$

$K_{w}^{(p)}=k_{d} \times\left(k_{a}+k_{b} R_{n}-k_{c} R_{n}^{2}\right) \times\left(\frac{S c_{l i q}}{600}\right)^{-n}$.

$K_{w}^{\prime}$ is the total water phase transfer velocity (to be used in Eq. 4), the superscript ( $p$ ) denotes "precipitation", $R_{n}$ is the rain rate in $\mathrm{mm} / \mathrm{h}$ and $K_{w}^{(p)}$ is in $\mathrm{m} / \mathrm{s}$. Here $k_{a}=0.929$, $k_{b}=0.679 \mathrm{~h} / \mathrm{mm}, \quad k_{c}=0.0015 \mathrm{~h}^{2} / \mathrm{mm}^{2}$, and $k_{d}=2.8 \times 10^{-6}$ $\mathrm{m} / \mathrm{s}$. The rain rate is obtained from other submodels for convective and large scale clouds.

As pointed out by Ho et al. (2004) more studies are required in this field, and the implementation of this feature has been included (selectable via the user interface), but by default, it is not activated.

For very soluble gases the gas phase can play a key role as a resistance against the exchange (see $R_{g}$ in Eq. 3).

The value of $K_{g}$ is given by:

$K_{g}=\frac{1}{R_{\mathrm{a}}+R_{\mathrm{qbr}}}$,

where $R_{\mathrm{a}}$ is the aerodynamic resistance and $R_{\mathrm{qbr}}$ is the quasi laminary boundary layer resistance (both in $\mathrm{s} / \mathrm{m}$ ).

For consistency with the other submodels of MESSy, in the default configuration of AIRSEA, $R_{\mathrm{a}}$ and $R_{\mathrm{qbr}}$ are calculated following Kerkweg et al. (2006a) (Eqs. 3 and 4 in the paper).

Alternatively one other parametrisation of these two resistances has been implemented, as suggested by Carpenter et al. (2004). Assuming a neutrally stable atmospheric surface layer, Garland (1977) used

$R_{\mathrm{a}}=\frac{U(z)}{u_{*}^{2}}$, where $U(z)$ is the wind speed at the height $\mathrm{z}$ of the lowest model layer and $u_{*}$ is the friction velocity (both in $\mathrm{m} / \mathrm{s}$ ). Further, the quasi laminary boundary layer resistance is given by Wesely (1989) as

$R_{\mathrm{qbr}}=\left(\frac{5}{u_{*}}\right) \mathrm{Sc}_{\mathrm{air}}{ }^{2 / 3}$,

where $\mathrm{Sc}_{\text {air }}$ is the dimensionless Schmidt number in air.

The Schmidt number in water is estimated from the Schmidt number for $\mathrm{CO}_{2}$. This approach is preferred to other methods, e.g., from direct measurements (Saltzmann et al., 1993), because these are not always available, and also because the parameterisation of $K_{w}$ has been mainly derived from $\mathrm{CO}_{2}$ measurements. Therefore, the Schmidt number for species $x$ is

$\mathrm{Sc}_{\mathrm{x}}=\left(\frac{v}{D_{x}}\right)=\mathrm{Sc}_{\mathrm{CO}_{2}}\left(\frac{D_{\mathrm{CO}_{2}}}{D_{x}}\right)$.

An expression for $D_{\mathrm{CO}_{2}} / D_{x}$ can be obtained Hayduk and Laudie (1974) or Wilke and Chang (1955) by

$\frac{D_{\mathrm{CO}_{2}}}{D_{x}}=\left(\frac{V_{x}}{V_{\mathrm{CO}_{2}}}\right)^{0.6}$,

where $V_{x}$ and $V_{\mathrm{CO}_{2}}$ are the molar volumes of the tracer and of $\mathrm{CO}_{2}$ at their boiling points at standard pressure, respectively. With this, a more realistic temperature dependence of the Schmidt number on the temperature of the seawater is achieved. Finally, the Schmidt number for $\mathrm{CO}_{2}$ can be calculated for sea-water using the relation given by Wanninkhof (1992):

$\mathrm{Sc}_{\mathrm{CO}_{2}}=k_{0}-k_{1} T+k_{2} T^{2}-k_{3} T^{3}$

with $T$ (temperature) in $\mathrm{K}, k_{0}=2073.1, k_{1}=125.62(1 / \mathrm{K})$, $k_{2}=3.6276\left(1 / \mathrm{K}^{2}\right)$, and $k_{3}=0.043219\left(1 / \mathrm{K}^{3}\right)$.

The diffusivity (in $\mathrm{m}^{2} \mathrm{~s}^{-1}$ ) of a tracer in air is calculated following the Fuller, Schettler and Giddings (FSG) method (Lyman et al., 1990):

$D_{x}=k \frac{10^{-11} T^{1.75} \sqrt{\frac{M_{a i r}+M_{x}}{M_{a i r} M_{x}}}}{p\left[V_{\text {air }}^{o}{ }^{1 / 3}+V_{x}^{o 1 / 3}\right]^{2}}$, 


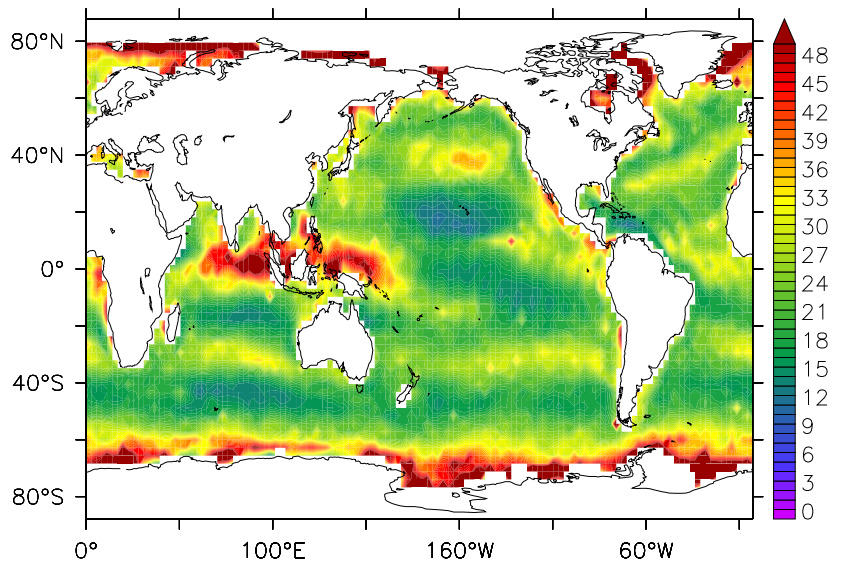

Fig. 1. Annual average time scale $\tau$ of air-sea exchange for $\mathrm{CO}_{2}$ in days. The height of the lowest model layer is $\approx 60 \mathrm{~m}$.

where $V_{x}^{o}$ is the molar volume based on the method developed by Fuller ( $\mathrm{in}^{3} / \mathrm{mol}$ ) which is equal to 0.8745 times the molar volume at boiling point, and $V_{\text {air }}^{o}$ is $20.1 \times 10^{-6}$ $\left(\mathrm{m}^{3} / \mathrm{mol}\right) . \quad T$ is the air temperature (in K), $M_{\text {air }}$ and $M_{x}$ are the molar masses of air and the tracer, respectively. $k=101325 \mathrm{Pam}^{4} \mathrm{~g}^{0.5} \mathrm{~s}^{-1} \mathrm{~mol}^{-0.167} \mathrm{~K}^{-1.75}$ is a constant used to obtain the right unit system.

\subsection{Time scale}

Ultimately, the change of concentration $c_{x}$ of a tracer $x$ in air above the ocean, is described by

$\frac{d c_{x}(t)}{d t}=\frac{K_{\mathrm{tot}}}{z}\left(c_{w}-c_{x}\right)$

where $c_{w}$ is the concentration of the tracer in the ocean water and $z$ is the height of the lowest model layer. This equation can be solved analytically, yielding

$c_{x}(t)=c_{0} e^{-\gamma t}+\left(1-e^{-\gamma t}\right) c_{w}$

with $\gamma=\frac{K_{\text {tot }}}{z}$. Equation (20) shows the typical time scale of the exchange process: $\tau=1 / \gamma$. This time scale depends on the tracer and the vertical model resolution.

As an example, Fig. 1 depicts the time scale $\tau$ for $\mathrm{CO}_{2}$. The magnitude of $\tau$ for this tracer is on the order of days to weeks; however, a large spatial variability is apparent. The shortest time scale (and hence highest transfer velocity) occurs in the storm track region, where high wind speeds are common. It has to be stressed that this is strictly valid only for this specific tracer. In case of a very soluble gas, in contrast, the temperature dependence of $K_{\text {tot }}$ can lead to a different result. The highest emission/deposition velocities are located in the tropical regions (where the ocean is warmest) and not where the highest wind speed occurs. Figure 2 depicts the transfer velocity for a soluble tracer (methanol), which shows the strong dependence of the transfer velocity on the temperature of the sea surface.

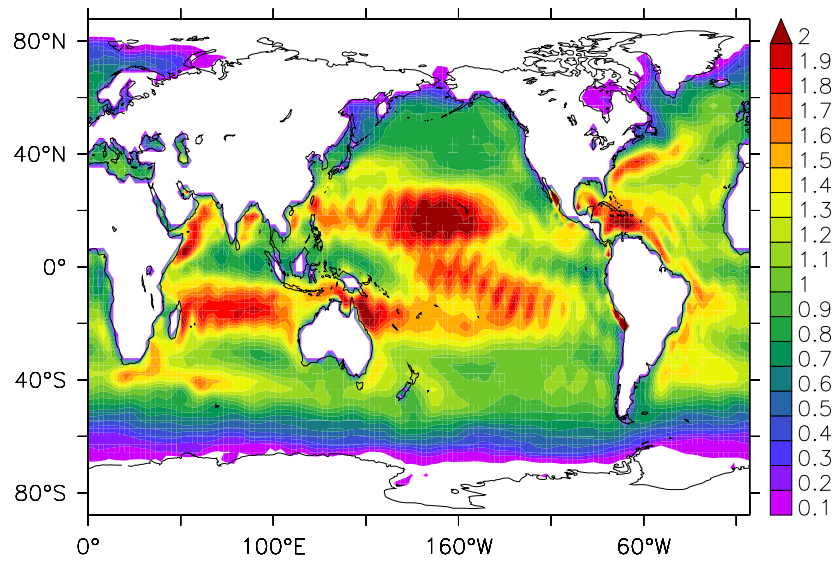

Fig. 2. Annual average transfer velocity $K_{\text {tot }}$ for $\mathrm{CH}_{3} \mathrm{OH}$ in $\mu \mathrm{m} / \mathrm{s}$.

\section{Implementation as MESSy submodel}

The implementation of the submodel AIRSEA described in Sect. 2 strictly follows the MESSy (Modular Earth Submodel System) standard (Jöckel et al., 2005); hence application to a general circulation model (GCM) is straightforward. AIRSEA is part of the MESSy model and available to the community. For details how to obtain the code, see http://www.messy-interface.org. The AIRSEA submodel, together with DRYDEP, OFFLEM, ONLEM, EMDEP and TNUDGE, accounts for the emission-deposition processes in the model. AIRSEA provides either a source or a sink of a tracer, following Eq. (1), depending on its concentrations in water and air. Particular attention has to be paid to other emission submodels to avoid double counting. Variables required for the calculation of the transfer velocity $K_{\text {tot }}$ (wind speed at 10 meters $\left(U_{10}\right)$, pressure, temperature (of air and surface), friction velocity $\left.\left(u_{*}\right)\right)$ are imported from the GCM via the MESSy data interface. The parameters specific for each tracer (e.g. molar volume at boiling point, Henry's Law coefficient, and molar mass) are provided via the user interface (Fortran90 namelist). More information about the AIRSEA namelist can be found in the electronic supplement of this paper (http://www.atmos-chem-phys.net/ 6/5435/2006/acp-6-5435-2006-supplement.pdf). This flexibility allows a large number of different studies without requiring a recompilation of the code. For instance, the calculation can also be performed for idealised tracers in process studies. The concentration of a specific tracer in ocean water, which is required for the calculation, can be

- provided by the user as constant value,

- provided from prescribed maps (e.g., climatologies) imported via the MESSy submodel OFFLEM (Kerkweg et al., 2006b), or

- provided directly (“online”) by ocean biogeochemistry submodels. 
In a model simulation including AIRSEA, the tracer concentrations (in air) are changed according to the air-sea exchange process (Eq. 19).

In every grid box of the lowest model layer, an additional tracer tendency is calculated

$$
\frac{\Delta c_{x}}{\Delta t}=\frac{c_{x}(t+\Delta t)-c_{x}(t)}{\Delta t},
$$

where $\Delta t$ is the model time step.

The signal is then transported to higher model layers by other processes, such as advection, convection, etc.

In Table 2 a list of the tracers tested in this submodel is presented, together with the values needed in the namelist file.

\section{Evaluation}

As shown in Sect. 3, AIRSEA can be easily applied to many types of tracers. Nevertheless, information about the sea water concentration of the tracers is required. This can be taken from available climatologies, parameterised, or derived directly from field studies. So far, measurements of organic compound concentrations are available for $\mathrm{CH}_{3} \mathrm{COCH}_{3}, \mathrm{CH}_{3} \mathrm{OH}, \mathrm{C}_{2} \mathrm{H}_{6}, \mathrm{C}_{2} \mathrm{H}_{4}, \mathrm{C}_{3} \mathrm{H}_{8}$ and $\mathrm{C}_{3} \mathrm{H}_{6}$ from Plass-Dülmer et al. (1995), Zhou and Mopper (1997), Zhou and Mopper (1993), Williams et al. (2004) and Sinha et al. (2006). However, as shown by Broadgate et al. (2000), the concentration during the seasonal cycle of these compounds can vary by an order of magnitude, and should not be neglected.

Unfortunately, measurements of organic species in the ocean are still rare. In fact, the very limited knowledge of the sea water concentration of the organic tracers currently represents the most important limitation in the application of this submodel.

Nevertheless, in the following we present three studies, showing the successful application of AIRSEA in a GCM. The studies have been performed with AIRSEA coupled to the atmospheric chemistry GCM ECHAM5/MESSy1 (Jöckel et al. (2006, and references therein), Roeckner et al. (2006)).

For the evaluation we first show that the simulated air-sea transfer velocity has the correct dependence on the solubility of the tracer (Sect. 4.1); then we compare simulated transfer velocities with satellite observations (Sect. 4.2); and finally we compare simulated mixing ratios of acetone with observations from a recent field campaign (Sect. 4.3).

\subsection{Liquid and gas phase transfer velocity}

With the "resistance exchange process", as described in Sect. 2, i.e., using the definitions Eq. (3), Eq. (4), and Eq. (12), we calculated the relative importance of gas phase and liquid phase resistance for the air-sea exchange process of $\mathrm{CO}_{2}$ and $\mathrm{CH}_{3} \mathrm{COCH}_{3}$.

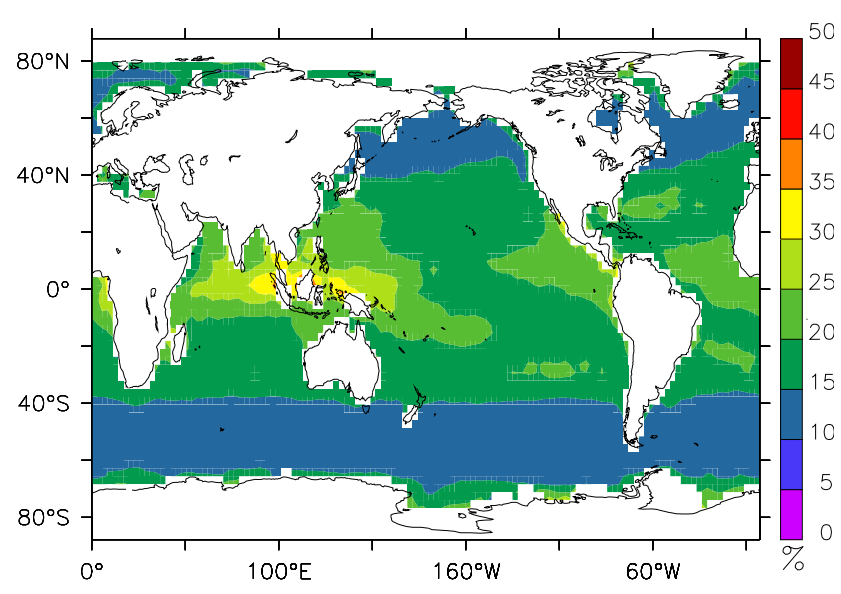

Fig. 3. Simulated annual average ratio between water and total resistance $\left(K_{\text {tot }} / K_{w}\right)$ for acetone $\left(\mathrm{CH}_{3} \mathrm{COCH}_{3}\right)$.

Soluble tracers have a relatively high resistance in the gasphase, and non-soluble tracers in the liquid-phase. For $\mathrm{CO}_{2}$, for instance, the total transfer velocity depends for more than $99 \%$ on the liquid phase transfer velocity, which is the classical approximation for modelling exchange rates of this tracer. The same calculation applied to a more soluble tracer, however, shows that the gas-phase resistance plays a major role. For acetone (see Fig. 3) the gas phase transfer velocity accounts for roughly $20 \%$ of the total transfer velocity.

\subsection{Transfer velocity and satellite measurements}

To test the output of the model we apply AIRSEA in ECHAM5/MESSy, whereby ECHAM5 is applied in a T42L19 resolution, forced only by sea-surface temperatures of AMIPII (Taylor et al., 2000) of the years 2000 to 2002. With input parameters for $\mathrm{CO}_{2}$ (see Sect. 3), we obtain a simulated climatology of the transfer velocity for $\mathrm{CO}_{2}$. Fig. 4 depicts the resulting annual zonal average transfer velocity $K_{\text {tot }}$. The results of the simulation are similar to the climatology obtained from satellite measurements (Boutin and Etcheto, 1997; Carr et al., 2002), demonstrating the successful implementation of the algorithm. Compared to Carr et al. (2002), the overall patterns are well reproduced. The highest transfer velocity is predicted at absolute latitudes higher than $40^{\circ}$, while the minimum is located at the equator. Differences can be found at low wind speed (equator): due to the use of instantaneous values of the wind speed, our calculation predicts much higher transfer velocities than Carr et al. (2002). As pointed out by Chapman et al. (2002), the use of non-averaged wind fields can increase the transfer velocity (and fluxes) of about $10 \%-60 \%$, with peaks up to $\approx 200 \%$. This is confirmed by the comparison with the climatology calculated by Boutin and Etcheto (1997), who obtained an annual global average $\mathrm{CO}_{2}$ transfer velocity of $3.15 \times 10^{-2} \mathrm{~mol} \mathrm{~m}^{-2} \mathrm{yr}^{-1} \mu \mathrm{atm}^{-1}$. This value is $40 \%$ lower 
Table 2. Tested tracers in the AIRSEA submodel with suggested values for the namelist.

\begin{tabular}{|c|c|c|c|c|c|c|c|}
\hline Tracer & $\begin{array}{l}\text { Molar } \\
\text { Mass } \\
{[\mathrm{g} / \mathrm{mol}]}\end{array}$ & $\begin{array}{c}\text { Henry's Law coefficient } \\
k_{H}^{\ominus} \\
{[\mathrm{M} / \mathrm{atm}]}\end{array}$ & $\begin{array}{c}a \\
\frac{\Delta_{\mathrm{soln}} H}{R} \\
{[\mathrm{~K}]}\end{array}$ & $\begin{array}{c}\text { Molar Volume } \\
\text { at boiling point } \\
{\left[\mathrm{cm}^{3} / \mathrm{mol}\right]}\end{array}$ & $\alpha$ & $\begin{array}{l}\text { Setschenow } \\
\text { constant } \\
{[\mathrm{L} / \mathrm{mol}]}\end{array}$ & $\begin{array}{c}\text { main reference for } \\
\text { liquid phase } \\
\text { concentration }\end{array}$ \\
\hline DMS & 62.13 & 0.48 & 3100 & $77.4^{b}$ & 1 & 0 & Kettle and Andreae (2000) \\
\hline $\mathrm{CO}_{2}$ & 44.0 & 3.6 & 2200 & $37.3^{b}$ & 1 & 0 & Takahashi et al. (2002) \\
\hline $\mathrm{CH} 3 \mathrm{OH}$ & 32.04 & $2.2 \times 10^{2}$ & 5600 & $42.5^{c}$ & 1 & 0 & Singh et al. (2003) \\
\hline $\mathrm{C}_{2} \mathrm{H}_{4}$ & 28.05 & $4.8 \times 10^{-3}$ & 1800 & $49.4^{c}$ & 1 & $0.127^{d}$ & Plass-Dülmer et al. (1995) \\
\hline $\mathrm{C}_{2} \mathrm{H}_{6}$ & 30.07 & $2.0 \times 10^{-3}$ & 2300 & $53.5^{c}$ & 1 & $0.162^{d}$ & Plass-Dülmer et al. (1995) \\
\hline $\mathrm{C}_{3} \mathrm{H}_{6}$ & 42.08 & $4.8 \times 10^{-3}$ & 3400 & $69.0^{c}$ & 1 & 0 & Plass-Dülmer et al. (1995) \\
\hline $\mathrm{C}_{3} \mathrm{H}_{8}$ & 44.09 & $1.5 \times 10^{-3}$ & 2700 & $74.5^{c}$ & 1 & 0 & Plass-Dülmer et al. (1995) \\
\hline $\mathrm{CH}_{3} \mathrm{COCH}_{3}$ & 58.08 & 30 & 4600 & $74^{c}$ & 1 & $0.11^{d}$ & Williams et al. (2004) \\
\hline ISOPRENE & 68.11 & $1.3 \times 10^{-2}$ & 0 & $103.6^{b}$ & 1 & 0 & Broadgate et al. (2000) \\
\hline
\end{tabular}

${ }^{a}$ Sander (1999b, and references therein)with $H(T)=k_{H}^{\ominus} \times \exp \left(-\frac{\Delta_{\mathrm{soln}} H}{R}\left(\frac{1}{T}-\frac{1}{T^{\ominus}}\right)\right), T^{\ominus}=298.15 \mathrm{~K}$

${ }^{b}$ LeBas method, LeBas (1915); Reid et al. (1984)

${ }^{c}$ Hayduk and Laudie (1974, and references therein)

${ }^{d} \mathrm{Ni}$ et al. (2000, and references therein)

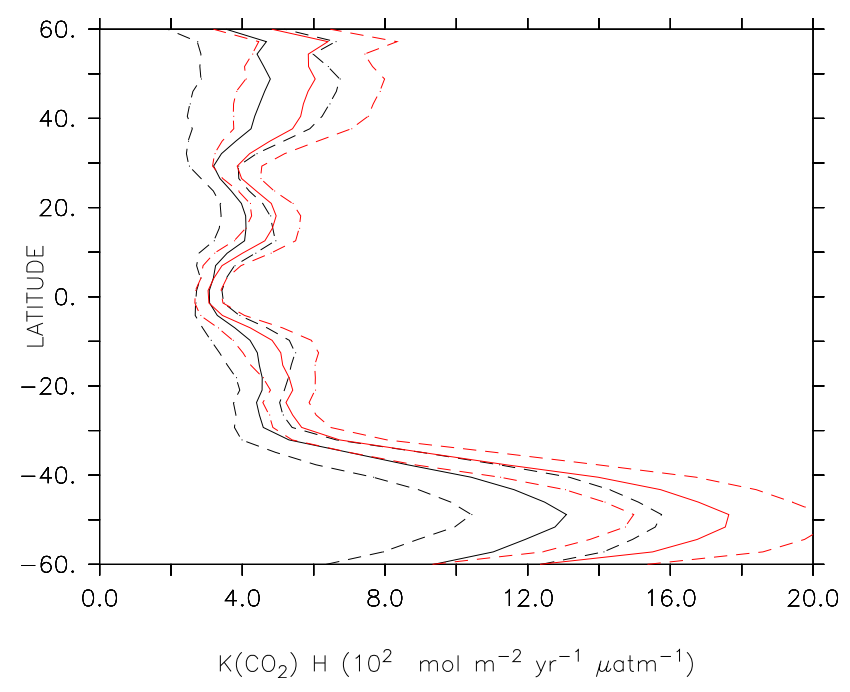

Fig. 4. Simulated annual zonal average transfer velocity for $\mathrm{CO}_{2}$. The red line shows the results obtained using Eq. (7) with the Wanninkhof (1992) parametrisation, the black line shows the results for which the whitecap parameterisation (Eq. 8) has been selected. Dashed lines are the standard deviations indicating the simulated variability in one year. The results are not weighted by ocean surface.

than $5.24 \times 10^{-2} \mathrm{~mol} \mathrm{~m}^{-2} \mathrm{yr}^{-1} \mu \mathrm{atm}^{-1}$ obtained by averaging our calculated transfer velocity.

Moreover, a realistic seasonal cycle of the transfer velocity is simulated, further supporting the correct implementation, and showing the effect of the sea surface temperature on the exchange process. In Fig. 5 the seasonal cycle over the Pacific Ocean is depicted; the lowest exchange rates occur around the equator, and the maximum at high southern latitudes in the storm tracks where the exchange rate is very

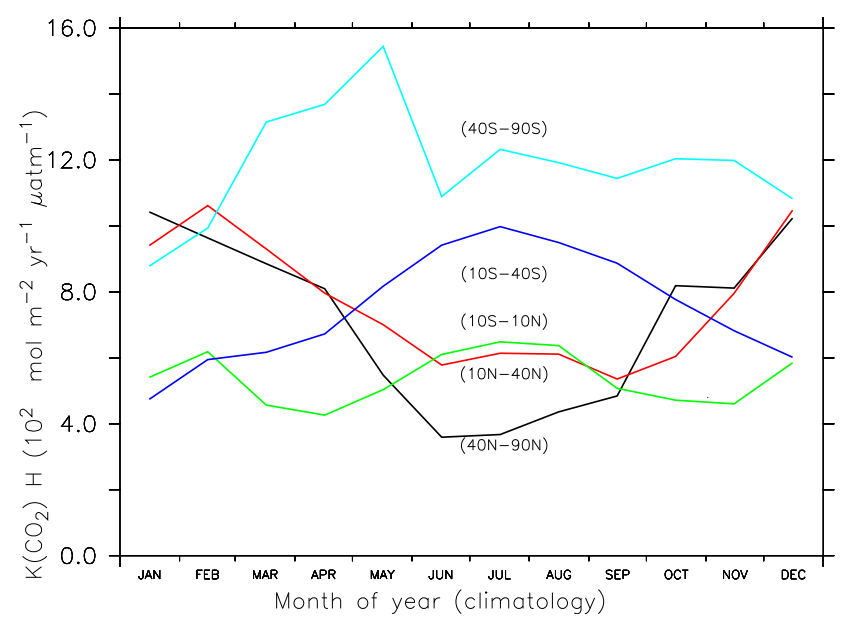

Fig. 5. Simulated seasonal cycle of the transfer velocity of $\mathrm{CO}_{2}$ over the Pacific Ocean for different latitude bands.

high due to the high wind speeds. A strong seasonal cycle is predicted in the subtropical region $\left(10^{\circ} \mathrm{N}-40^{\circ} \mathrm{N}\right.$ and $10^{\circ} \mathrm{S}-40^{\circ} \mathrm{S}$ ) where the sea surface temperature amplitude is higher than in other regions. This agreement between satellite observation and model simulation corroborates the correct implementation of the algorithm. AIRSEA yelds similar results as those calculated from satellite observations with the same equations. Figure 4 shows that the differences of Eq. (7) (Wanninkhof, 1992) and of Eq. (8) are quite consistent. The Wanninkhof (1992) parametrisation predicts higher transfer velocities with a maximum difference of 0.04 mol m${ }^{-2} \mathrm{yr}^{-1} \mu_{\mathrm{atm}}{ }^{-1}$; however, the equatorial minimum is simulated almost identically. This is due to the parametrisation in Eq. (8), where the bubble enhancement of the transfer velocity is highly dependent on the tracer solubility (Ostwald 


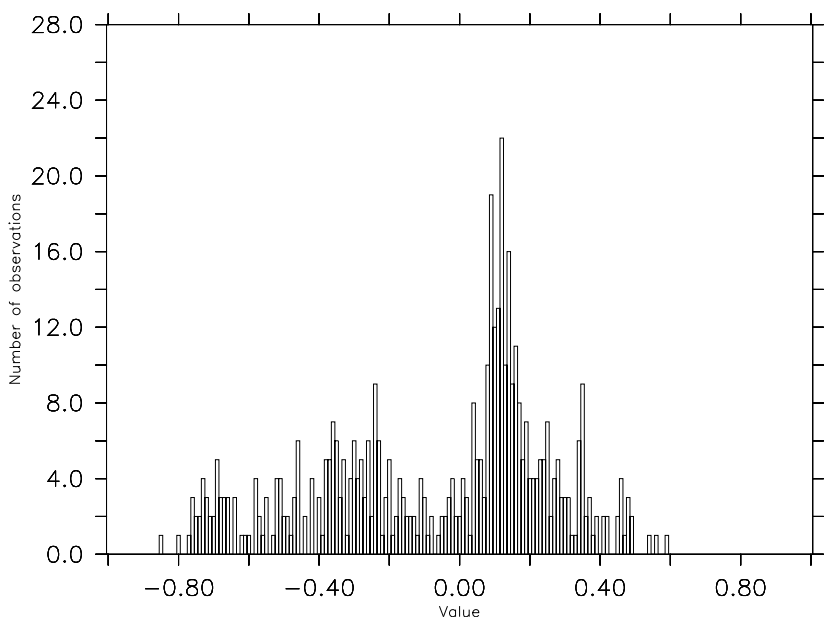

Fig. 6. Histogram of differences (in $\mathrm{nmol} / \mathrm{mol}$ ) between the observations and the ECHAM5/MESSy simulation (T42L90MA, reference simulation) without the submodel AIRSEA.

number). As an example, for $\mathrm{CO}_{2}$ and a sea surface temperature of $280 \mathrm{~K}$, Eq. (8) predicts higher values than Eq. (7) only for $U_{10}$ lower than $7 \mathrm{~m} / \mathrm{s}$.

\subsection{Meteor 55 ship cruise}

The submodel has been further evaluated using measurements of VOCs over the tropical Atlantic Ocean during Cruise 55 of the research ship Meteor (Williams et al., 2004) (further denoted as METEOR55 campaign). During this campaign (October-November 2002) several organic compounds have been measured in air and in ocean surface water. The ship track was from Curacao $\left(69^{\circ} \mathrm{W}\right)$ to Cameroon $\left(9^{\circ} \mathrm{E}\right)$, approximately along $10^{\circ} \mathrm{N}$. From 13 October 2002 to 15 November 2002 the sea surface concentration of acetone, methanol, DMS and acetonitrile have been collected hourly. We performed a model simulation, for the period of the campaign in autumn 2002, to test the AIRSEA submodel. The resolution used is T42L90MA $\left(\sim 2.8^{\circ}\right.$ horizontal resolution of the corresponding quadratic Gaussian grid, and 90 vertical layers up to $0.01 \mathrm{hPa}$ ). The set-up of the simulation is exactly the same as described in Jöckel et al. (2006) with the only exception of activating the AIRSEA submodel.

We present a one-to-one comparison for acetone, which is moderately soluble. This means that both phases (liquid and gas) are important and influence the air-sea exchange process. This implies that acetone is one of the most complex tracers for which we can compare our model results.

In the absence of a more extensive dataset, we had to make the idealised assumption of a constant concentration of acetone in sea water. This is clearly not representative for the globe, but acceptable for the region around the ship track. A constant concentration of $14 \mathrm{nmol} / \mathrm{L}$ was assumed. This values is based on the average of the measured concentrations during the METEOR55 campaign, taking into account

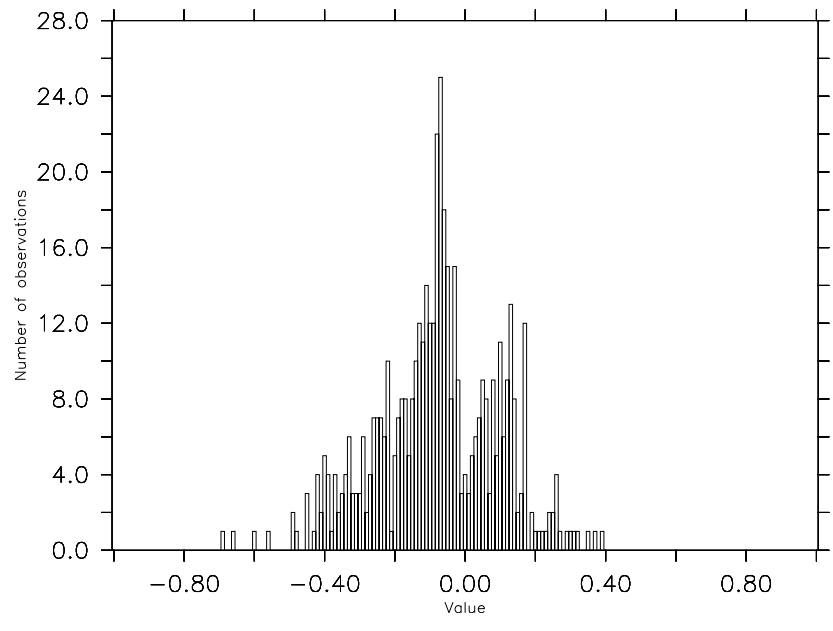

Fig. 7. Histogram of differences (in $\mathrm{nmol} / \mathrm{mol}$ ) between the observations and the ECHAM5/MESSy simulation (T42L90MA) with the submodel AIRSEA.

the temperature and salinity effect on the Henry's law coefficient.

Figures 6 and 7 show the distributions of the point-to-point differences $(\approx 500$ points) between the model results and the observations of the atmospheric mixing ratio of acetone, calculated without and with AIRSEA, respectively. The improvement through accounting for the air-sea exchange process is obvious.

The observed average is $0.53 \mathrm{nmol} / \mathrm{mol}$, while the simulated averages of the model without and with AIRSEA are $0.63 \mathrm{nmol} / \mathrm{mol}$ and $0.64 \mathrm{nmol} / \mathrm{mol}$, respectively. Although the averaged bias between model results and measurements is almost unchanged $(\approx 0.1 \mathrm{nmol} / \mathrm{mol}$ in both cases), with AIRSEA the difference distribution is narrower and more centered around zero.

Without AIRSEA, deviations between model results and observations frequently exceed $0.4 \mathrm{nmol} / \mathrm{mol}$, which is close to the average observed mixing ratio of $0.53 \mathrm{nmol} / \mathrm{mol}$.

The root mean square deviation (RMS) confirms this visual impression. The model simulation without AIRSEA yields a RMS of $0.165 \mathrm{nmol} / \mathrm{mol}$, while with the AIRSEA submodel the RMS is reduced to $0.061 \mathrm{nmol} / \mathrm{mol}$.

Figure 8 shows that by applying AIRSEA, the simulated acetone mixing ratio changes strongly in the marine boundary layer. In the simulation with the new submodel the mixing ratios in the tropics are generally higher. Figure 9 shows the relative changes throughout the troposphere during a single day. This daily average is for the 5th of November, in the midst of the METEOR55 campaign, on which we are focusing the analysis. The model is performing better than previously (Figs. 6-7) and we obtain drastical changes in the marine boundary layer (Fig. 9). In the tropics, especially south of the Intertropical Convergence Zone (ITCZ), where atmospheric acetone is generally lower than to the 


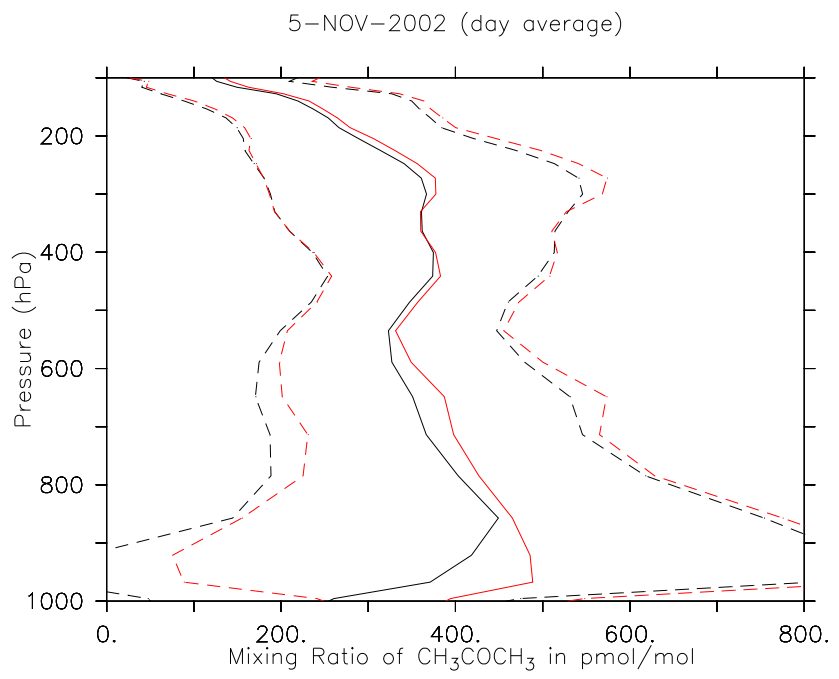

Fig. 8. Example of the vertical acetone $\left(\mathrm{CH}_{3} \mathrm{COCH}_{3}\right)$ profile simulated by ECHAM5/MESSy (T42L90MA, reference simulation, in black) and ECHAM5/MESSy with the submodel AIRSEA (red). The profiles represent a one day average over the region where the campaign METEOR55 took place. The dashed lines represent the corresponding spatial standard deviations.

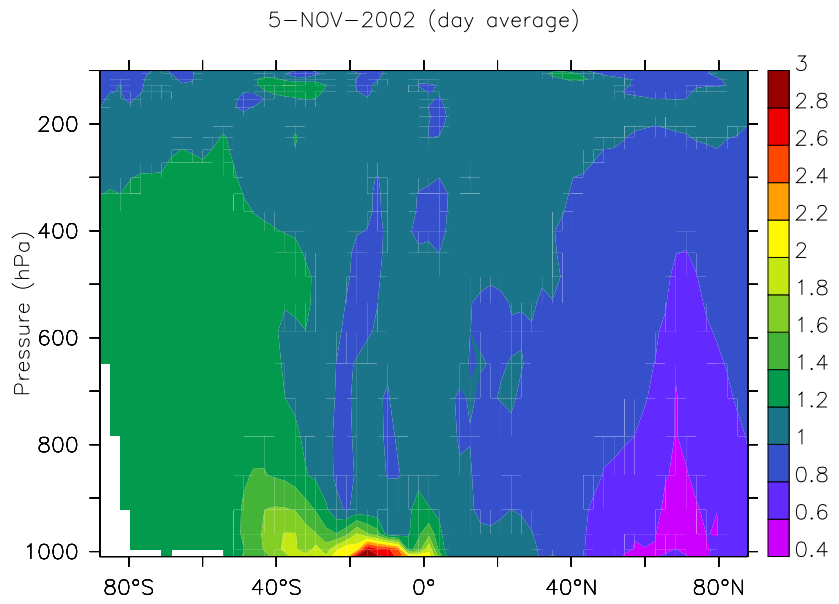

Fig. 9. Relative change of the acetone mixing ratio comparing the submodel AIRSEA in ECHAM5/MESSy with the reference simulation for a one day average (November 2002). The values have been zonally averaged over the Atlantic Ocean.

north, increases up to a factor of 3 are simulated. In the northern hemisphere over the Atlantic Ocean during this period the atmospheric mixing ratios generally decrease by up to $50 \%$ or more. Although the simulated north-south distribution of acetone changes substantially, the overall tropospheric mean mixing ratio changes less than $15 \%$. However, the application of such a limited dataset for extrapolating to the global scale should not be overrated.

\section{Conclusions}

The MESSy submodel AIRSEA for the calculation of the airsea exchange of chemical constituents has been presented. The implementation of a more mechanistic approach permits an easy extension of the model to a wide variety of tracers, allowing also process studies.

The realistic description of this process and the low computational requirements can be expected to improve the ability of global models to predict the chemical composition of the atmosphere.

This is especially required for the interpretation of observational data, notably for data obtained on ships.

Currently, the major limitation of this approach is, however, a good characterisation of the water concentration of the tracers. Additional measurements are needed to improve our knowledge in this field.

Acknowledgements. Thanks to the MESSy team for the helpful suggestions and comments. The authors wish to acknowledge the use of the Ferret program for analysis and graphics in this paper. Ferret is a product of NOAA's Pacific Marine Environmental Laboratory (Information is available at http://www.ferret.noaa.gov).

Edited by: M. Dameris

\section{References}

Asher, W. and Pankow, J.: Prediction of Gas/Water mass transport coefficients by a surface renewal model, Environ. Sci. Technol., 25, 1294-1300, 1991.

Asher, W. and Wanninkhof, R.: The effect of bubble-mediated gas transfer on purposeful gaseous tracer experiments, J. Geophys. Res., 103, 10 555-10 560, 1998a.

Asher, W. and Wanninkhof, R.: Transient tracers and air-sea gas transfer, J. Geophys. Res., 103, 15 939-15 958, 1998b.

Berner, U., Poggenburg, J., Faber, E., Quadfasel, D., and Frische, A.: Methane in ocean waters of the Bay of Bengal: its sources and exchange with the atmosphere, Deep-Sea Res. II, 50, 925950, 2003.

Boutin, J. and Etcheto, J.: Long-term variability of the air-sea $\mathrm{CO}_{2}$ exchange coefficient: Consequence for the $\mathrm{CO}_{2}$ fuxes in the equatorial Pacific Ocean, Global Biogeochem. Cycles, 11, 453470, 1997.

Boyer, T., Stephens, C., Antonov, J., Conkright, M., Locarnini, R., O'Brien, T., and Garcia, H.: World Ocean Atlas 2001, Volume 2: Salinity, p. 167 pp., NOOA Atlas NESDIS 50, U.S. Government Printing Office, 2002.

Broadgate, W., Liss, P., and Penkett, A.: Seasonal emission of isoprene and other reactive hydrocarbon gases from the ocean, Geophys. Res. Lett., 24, 2675-2678, 2000.

Carpenter, L., Alastair, C., and Hopkin, J.: Uptake of methanol to the North Atlantic Ocean surface, Global Biogeochem. Cycles, 18, doi:10.1029/2004GB002 294, 2004.

Carr, M.-E., Wenquing, T., and Liu, W.: $\mathrm{CO}_{2}$ exchange coefficients from remotely sensed wind speed measurements: 
SSM/I versus QuikSCAT in 2000, Geophys. Res. Lett., 29, doi:10.1029/2002GL015 068, 2002.

Chapman, E., Shaw, W. J., Easter, R. C., Bian, X., and Ghan, S. J.: Influence of wind speed averaging on estimates of dimethylsulfide emission fluxes, J. Geophys. Res., 107, doi:10.1029/2001JD001 564, 2002.

Garland, J.: The dry deposition of sulphur dioxide to land and water surfaces, Proc. R. Soc. London, 354, 245-268, 1977.

Hayduk, W. and Laudie, H.: Prediction of diffusion coefficients for nonelectrolytes in diluite aqueous solutions, AIChE J., 20, 611615, 1974.

Ho, D., Zappa, C., McGills, W., Bliven, L., Ward, B., Dacey, J., Schlosser, P., and Hendricks, M.: influence of rain on air-sea gas exchange: Lesson from a model ocean, J. Geophys. Res., 109, doi:10.1029/2003JC001 806, 2004.

Ho, D., Cliff, S., Murray, A. L., Smith, J., Schlosser, P., Harvey, M., and Hill, P.: Measurements of air-sea gas exchange at high wind speeds in the Southern Ocean: Implications for global parameterizations, Geophys. Res. Lett., 33, doi:10.1029/2006GL026 817, 2006.

Jähne, B., Muennich, K., Boesinger, R., Dutzi, A., Huber, W., and Libner, P.: On parameter influencing the air-water gas exchange, J. Geophys. Res., 92, 1937-1949, 1987.

Jöckel, P., Sander, R., Kerkweg, A., Tost, H., and Lelieveld, J.: Technical Note: The Modular Earth Submodel System (MESSy) - a new approach towards Earth System Modeling, Atmos. Chem. Phys., 5, 433-444, 2005, http://www.atmos-chem-phys.net/5/433/2005/.

Jöckel, P., Tost, H., Pozzer, A., Brühl, C., Bucholz, J., L., G., Hoor, P., Kerkweg, A., Lawrence, M., Sander, R., Steil, B., Stiller, G., Tanarhte, M., Taraborrelli, D., van Aardenne, J., and Lelieveld, J.: Evaluation of the atmospheric chemistry GCM ECHAM5/MESSy: Consistent simulation of ozone in the stratosphere and troposphere, Atmos. Chem. Phys., 6, 5067-5104, 2006, http://www.atmos-chem-phys.net/6/5067/2006/.

Kerkweg, A., Buchholz, J., Ganzeveld, L., Pozzer, A., Tost, H., and Jöckel, P.: Technical Note: An implementation of the dry removal processes DRY DEPosition and SEDImentation in the Modular Earth Submodel System (MESSy), Atmos. Chem. Phys., 6, 4617-4632, 2006a.

Kerkweg, A., Sander, R., Tost, H., and Jöckel, P.: Technical Note: Implementation of prescribed (OFFLEM), calculated (ONLEM), and pseudo-emissions (TNUDGE) of chemical species in the Modular Earth Submodel System (MESSy), Atmos. Chem. Phys., 6, 3603-3609, 2006b.

Kettle, A. J. and Andreae, M.: Flux of dimethylsulfide from the oceans: A comparison of updated data set and flux models, J. Geophys. Res., 105, 26 793-26 808, 2000.

LeBas, G.: The Molecular Volumes of Liquid Chemical Compounds, in The Properties of Gases and Liquids, Monograph Longmans, Green, 1915.

Liss, P. and Merlivat, L.: Air-sea gas exchange rates: Introduction and synthesis, in The Role of Air-Sea Exchange in Geochemical Cycling, pp. 113-127, P. Buat-Menard, 1986.

Liss, P. and Slater, P.: Flux of gases across the air-sea interface, Nature, 247, 181-184, 1974.

Lyman, W., Reehl, W., and Rosenblatt, D.: Handbook of chemical property estimation mehods, American Chemical Society, Wash- ington DC, USA, 1990.

Marandino, C., De Bruyn, W., Miller, S., Prather, M., and Saltzmann, E.: Oceanic uptake and the global atmospheric acetone budget, Geophys. Res. Lett., 32, doi:10.1029/2005GL023 285, 2005.

Monahan, E.: Occurrence and evolution of acustically relevant sub surface bubble plumes and their associated, remotely monitorable, surface withecaps, in Natural Physical Sources of Underwater Sound, edited by B. Kerman, pp. 503-517, Kluwer Acad., 1993.

Ni, N., El-Sayed, M., Sanghvi, T., and Yalkowsky, S.: Estimation of the effect of $\mathrm{NaCl}$ on the solubility of organic compounds in aqueous solutions, J. Pharm. Sci., 89, 1620-1625, 2000.

Nightingale, P. D., Malin, G., Law, C. S., Watson, A. J., Liss, P. S., Liddicoat, M. I., Boutin, J., and Upstill-Goddard, R. C.: In situ evaluation of air-sea gas exchange parametrizations using novel conservsative and volatile tracers, Global Biogeochem. Cyc., 14, 373-387, 2000.

Plass-Dülmer, C., Koppman, R., Ratte, M., and Rudolph, J.: Light nonmethane hydrocarbons in seawater, Global Biogeochem. Cyc., 9, 79-100, 1995.

Reid, R., Pransnitz, J., and Poling, B.: The Molecular Volumes of Liquid Chemical Compounds, in The Properties of Gases and Liquids, 3rd edition, McGraw Hill, New York, 1984.

Roeckner, E., Brokopf, R., Esch, M., Giorgetta, M., Hagemann, S., Kornblueh, L., Manzini, E., Schlese, U., and Schulzweida, U.: Sensitivity of simulated climate to horizontal and vertical resolution in the ECHAM5 atmosphere model, J. Clim., 19, 37713791, 2006.

Saltzmann, E., King, D., K., H., and C., L.: Experimental determination of the diffusion coefficient of dimethylsulfide in water, J. Geophys. Res., 98, 16481-16486, 1993.

Sander, R.: Modeling atmospheric chemistry: Interactions between gas-phase species and liquid cloud/aerosol particles, Surv. Geophys., 20, 1-31, 1999a.

Sander, R.: Compilation of Henry's law constant for inorganic and organic species of potential importance in environmental chemistry, http://www.henrys-law.org, 1999b.

Singh, H., Chen, Y., Staudt, A. C., Jacob, D. J., Blake, D. R., Heikes, B. G., and Snow, J.: Evidence from the Pacific troposphere for large global sources of oxygenated organic compounds, Nature, 410, 1078-1081, 2001.

Singh, H. B., Tabazadeh, A., Evans, M. J., Field, B. D., Jacob, D. J., Sachse, G., Crawford, J. H., Shetter, R., and Brune, W. H.: Oxygenated volatile organic chemicals in the oceans: Inferences and implications based on atmospheric observations and air-sea exchange models, Geophys. Res. Lett., 30, 1862, doi:10.1029/2003GL017 933, 2003.

Sinha, V., Williams, J., Meyerhfer, M., Riebesell, U., Paulino, A. I., and Larsen, A.: Air-sea fluxes of methanol, acetone, acetaldehyde, isoprene and DMS from a Norwegian fjord following a phytoplankton bloom in a mesocosm experiment, Atmos. Chem. Phys. Discuss., 6, 9907 9935, 2006,

http://www.atmos-chem-phys-discuss.net/6/9907/2006/.

Soloviev, A. and Schluessel, P.: A model of air-sea gas exchange incorporating physics of the turbulent boundary layer and the properties of the sea surface, in Gas transfer at water surface, edited by M. Donelan, W. Drennan, M. Saltzmann, and R. Wanninkhof, pp. 141-146, Geophysical Monograph, 2002. 
Takahashi, T., Sutherland, S. C., Sweeney, C., Poisson, A., Metzl, N., Tilbrook, B., Bates, N., Wanninkhof, R., Feely, R. A., Sabine, C., Olafsson, J., and Nojiri, Y.: Global sea air $\mathrm{CO}_{2}$ flux based on climatological surface ocean $p \mathrm{CO}_{2}$, and seasonal biological and temperature effects, Deep-Sea Res. II, 49, 1601-1622, 2002.

Taylor, K., Williamson, D., and Zwiers, F.: The sea surface temperature and sea ice concentration boundary conditions for AMIP II simulations; PCMDI Report, Tech. Rep. 60, Program for Climate Model Diagnosis and Intercomparison, 2000.

Wanninkhof, R.: Relationship between wind speed and gas exchange over the ocean, J. Geophys. Res., 97, 7373-7382, 1992.

Wanninkhof, R. and McGills, W. R.: A cubic relationship between air-sea $\mathrm{CO}_{2}$ exchange and wind speed, Geophys. Res. Lett., 26, 1889-1892, 1999.

Wesely, M.: Paramatrization of surface resistances to gaseous dry deposition in regional-scale numerical models, Atmos. Environ., 23, 1293-1304, 1989.

Wilke, C. and Chang, P.: Correlation of diffusion coefficients in diluite solutions, AIChE J., 1, 264-270, 1955.
Williams, J., Holzinger, R., Gros, V., Xu, X., Atlas, E., and Wallace, D.: Measuremets of organic species in air and seawater from the tropical Atlantic, Geophys. Res. Lett., 31, doi:10.1029/2004GL02 001, 2004.

Xie, W., Su, J., and Xie, X.: Studies on the activity coefficients of benzene an its derivatives in aqueous salt solution., Thermochimica Acta, 169, 271-286, 1990.

Xie, W., Shiu, W., and Mackay, D.: A review of the effect of salt on the solubility of organic compounds in seawater, Mar. Environ. Res., 44, 429-444, 1997.

Zhou, X. and Mopper, K.: Carbonyl compounds in the lower marine troposphere over the Carribean sea and Bahamas, J. Geophys. Res., 98, 2385-2392, 1993.

Zhou, X. and Mopper, K.: Photochemical production of lowmolecular weight compounds in seawater and surface microlayer and their air-sea exchange, Mar. Chem., 56, 201-213, 1997. 